Symposium: 12th International Symposium on Rolling Bearing Steels - Progress in Bearing Steel Metallurgical Testing and Quality Assurance

\title{
Improved Processing Techniques for Inclusion-Free Steel for Bearing and Mechanical Component Applications
}

\author{
Christopher DellaCorte
}

\begin{abstract}
High-hardness, high-carbide powder metallurgy tool steels such as M62 enable the use of ball bearings at extremely high load and stress levels. Operation under such conditions increases the potential for rolling contact fatigue failure attributed to nonmetallic inclusions. To address this challenge, industry has sought ever-cleaner steels, but the results have been uneven, owing to the random nature of the occurrence of such material flaws. Careful melting processes and thorough ingot inspections prior to bearing manufacture are common approaches to avoid inclusions. Selecting only the cleanest portions of an ingot may result in bearings relatively free from material flaws. This approach is not always successful because detrimental flaws that exist deep within an ingot can pass inspections undetected, potentially causing subsequent failure.
\end{abstract}

Recent efforts to commercialize an intermetallic material, $60 \mathrm{NiTi}$, for rolling element bearings demonstrates a pathway to produce bearing steel that is free from unwanted ceramic particle inclusions. In this paper, the process used to make bearing-grade inclusion-free NiTi alloys is

NASA Glenn Research Center, Cleveland, Ohio, 44135, USA; ORCID (Note: Go to www.orcid.org for details)

Page 1 of 30 
described and applied to steelmaking. At its core, the NiTi process differs from steelmaking in one key aspect. NiTi alloys are made from elementally pure starting materials that are melted, blended, and processed in equipment that minimizes exposure to oxygen and other sources of contamination, ensuring an inclusion-free product. In contrast, the predominant method to make bearing steel is to employ a successive series of melt purification steps to reduce contamination levels below required thresholds.

This paper describes the processes developed and applied to high-carbide tool steel, M62. The resulting material and microstructures are evaluated and compared to M62 prepared by conventional powder production and consolidation techniques. It is hoped that the application of materials manufacturing techniques used for fracture-sensitive ceramics and intermetallic materials like NiTi can provide a pathway to nonmetallic inclusion-free steels for rolling element bearings and other failure critical applications.

\section{Keywords}

steel, inclusions, processing, M62 tool steel, powder metallurgy, bearing steel, mechanical components

\section{Introduction}

As machine power density rises and system efficiency requirements advance, the stresses and loads placed on mechanical components such as ball bearings have seen a rapid increase [1]. For this reason, bearing failures that have been attributed to ceramic particle contamination

(inclusions) are becoming more prevalent [2]. Further, newer higher load capacity and 
performance bearing steels are more brittle than conventional steels and more prone to brittle fracture failure. One specific high-performance steel alloy of this type is called M62 (trade names $\mathrm{CPM}^{\star} \mathrm{REX}^{\star} 20$ (Crucible Industries), $\mathrm{CPM}^{\circledR} \mathrm{Vim}^{\mathrm{CR}} \mathrm{CR}^{\star} 20^{\star}$ (Crucible Industries)) [1-3].

M62 is super-hard steel with a very high percentage of carbide phase constituents. It is often used as a cutting tool alloy. To be used as bearing steel, it must be cast and hot rolled to break up unavoidable ceramic particle contaminants and to minimize the size of these flaws. In some cases, the resulting M62 is processed through powder metallurgy (PM) methods where the material is atomized into fine powder and then consolidated. Only through these multistep processes has it been possible to produce high-performing ball bearings [4]. Recently, however, with the increase in load levels and the decrease in bearing size, even M62 produced as described is subject to failure. Efforts by the steel industry to overcome this challenge have met uneven success.

One approach has been to carefully inspect M62 ingots prior to bearing manufacture. By selecting the cleanest portion of an ingot, it has been hoped that bearings relatively free from material flaws will result. This approach is not always successful because detrimental flaws that exist deep within an ingot can pass inspection undetected only to cause bearing failure in use [5]. Another approach is to pour the cast and molten steel through fine mesh filters to attempt to screen out large contaminant particles. Alternatively, one can add extra elements and compounds to the molten steel to cause the coagulation and precipitation of tramp and contaminant phases that then either float to the top of the melt for removal or settle to the bottom so they can be avoided in the final product. Though the bearing industry has tried many approaches to using advanced but traditional techniques to produce ceramic-free steel, none have completely succeeded [6, 7]. 
Recent efforts to commercialize an intermetallic material, $60 \mathrm{NiTi}$, for rolling element bearings may offer insight for the production of bearing steel that is free from unwanted ceramic particle inclusions. In this paper, the highly controlled, intrinsically clean (free from ceramic particle contamination routes) process used to make bearing-grade NiTi alloys is described. This process is applied to M62 tool steel and the resulting material and microstructures are evaluated. It is hoped that the application of materials manufacturing techniques used for fracture-sensitive ceramics and intermetallic materials can provide a pathway to clean, ceramic inclusion-free steels for rolling element bearings and other applications.

\section{Background}

In 2004, National Aeronautics and Space Administration (NASA) Glenn Research Center researchers began the development of the alloy $60 \mathrm{NiTi}(60 \mathrm{wt} \% \mathrm{Ni}, 40 \mathrm{wt} \% \mathrm{Ti})$ for ball bearing and mechanical component applications $[8,9]$. NiTi is an ordered intermetallic material with atomiclevel bonding that falls midway between metallic bonds, which share electrons, and covalent or ceramic bonds, which swap electrons. For this reason, NiTi exhibits some characteristics of metals and ceramics. For instance, like metals, NiTi alloys have a shiny appearance, are electrically conductive, and can be machined with conventional metalworking tools, like ceramic materials, NiTi is chemically inert and prone to brittle fracture [10]. In addition, when properly processed and heat treated, select NiTi compositions (nickel-rich such as 60NiTi) can reach high hardness levels suitable for bearings.

To prevent fracture in NiTi alloys, it is vital that the material is as homogeneous as possible 
and free from porosity and other flaws, especially hard particle contamination sometimes referred to as "ceramic inclusions." Such flaws act as locations for stress concentration and are initiation sites for catastrophic fracture. Indeed, early work on nickel-rich NiTi alloys from the 1950s identified spontaneous fracture as an obstacle to the successful use of the technology [11].

The materials engineering community has long relied upon flaw prevention and flaw size minimization approaches as a means to avoid fracture tendencies in brittle materials like ceramics [12]. For nickel-rich NiTi alloys, which are also brittle, NASA adopted several flaw prevention and minimization methods to produce high-quality material that has been proven in high-stress, long-life ball bearing applications. A new NASA Materials and Processing (M\&P) specification and several U.S. patents describe the general approach to the production of NiTi bearing materials that are largely free from ceramic particle inclusions and other flaws [13-17]. The general process briefly follows.

NiTi electrodes are made by melting high-purity individual elements (nickel and titanium) in a vacuum furnace. Care is taken to prevent the molten elements from coming into contact with any ceramic materials or containers that might contaminate the NiTi. The resulting NiTi is cast into a metal mold and the resulting ingot is turned into a rod, typically 50 to $75 \mathrm{~mm}$ in diameter and 500 to $1500 \mathrm{~mm}$ long, that is used as feedstock for further processing into a fine powder by gas atomization. The powder is made by melting the surface of the NiTi rod inside an inert gas filled chamber, causing drops of molten alloy to fall into an inert gas stream, where it is broken into finer droplets that solidify into extremely fine, pure NiTi powder. At no point during the processing does the material come into contact with any ceramic surfaces. The resulting powder is of high 
purity and sieved into a narrow size range ( $\sim 50$ to $250 \mu \mathrm{m}$ diameter). The powder is placed into clean steel containers that are then sealed and consolidated at high pressures and temperatures into PM compacts, also known as a billet. The size of the billets vary depending upon the desired shape and size of the end product. For research purposes, billets $25-50 \mathrm{~mm}$ in diameter and 100 to 500 $\mathrm{mm}$ long are typical. When making bearing races, billet diameters are often chosen to be slightly larger than the intended bearing race outside diameter and can include a solid steel core sized just below the desired bearing race inside diameter to conserve the costly NiTi material. The billets, when examined under a microscope, are free from ceramic particle inclusions and any minor remaining flaws, such as residual porosity, are much smaller than the original particle size and do not lead to fracture.

This approach to manufacturing NiTi alloy material largely free from ceramic inclusions and small-scale flaws is a reliable and practical method for making high-quality, yet still brittle, material suitable for bearings [8,9]. Such extreme measures, however, are not considered necessary for making bearings from steel because the intrinsic ductile nature of iron alloys from which bearing steel is made is considered less sensitive to fracture than ceramics and ordered intermetallics [18]. For certain high-stress applications that utilize less ductile, high-hardness tool steels, like M62, processing via the described NiTi method could result in improved M62 steel free from deleterious ceramic inclusions with enhanced capabilities when used in rolling element bearings.

In the following sections, experiments are undertaken to apply the described NiTi process method to M62 tool steel. First, elementally pure raw ingredients are sourced and combined 
(melted) in an all-metal crucible using the cold hearth plasma process. The M62 electrodes were $50 \mathrm{~mm}$ in diameter and $500 \mathrm{~mm}$ long prior to atomization. The resulting clean cast steel is then turned into powder using a specialized atomization system that does not utilize any ceramic components that could introduce ceramic particle inclusions. The atomized powder is then hot isostatic pressed into a fully dense ingot, which is evaluated for microstructure and the uniformity. For the initial trials, the HIP ingot was $25 \mathrm{~mm}$ in diameter and $300 \mathrm{~mm}$ long. Follow up ingots were also cylindrical in shape and were $150 \mathrm{~mm}$ in diameter and $100 \mathrm{~mm}$ long.

\section{Materials and Methods}

The high-performance, high-carbide tool steel AISI M62, also known as $\mathrm{CPM}^{\circledR} \mathrm{REX}^{\circledR} 20$, is selected for this investigation [19]. The nominal composition of M62 is given in Table 1. Typical material properties follow in Table 2 [19]. The first process step is to carefully select the starting materials. Rather than starting with steel scrap and adjusting the composition through the addition and removal of constituents and impurities, for this investigation, laboratory grade, high-purity (99.9\% or better) individual elements (iron, carbon, vanadium, tungsten, molybdenum and chromium, manganese, and silicon) are commercially sourced (e.g. Fisher Scientific, Alfa-Aesar, etc.). All of the elements were in powder form except for the vanadium and chromium which were in chunk form. The use of high-grade individual elements avoids the potential for carryover of preexisting ceramic particle contaminants into the finished product. It is well appreciated that these starting materials may be economically infeasible for many applications. However, for the purposes of the present investigation, cost is not under consideration. Rather, determining the technical feasibility of the ceramic-free process route is the primary goal.

\section{Table 1-Nominal Composition (weight \%) of M62}




\begin{tabular}{|c|c|c|c|c|c|c|c|c|}
\hline Element & $\mathrm{Fe}$ & $\mathrm{C}$ & $\mathrm{Mn}$ & $\mathrm{Si}$ & $\mathrm{Cr}$ & $\mathrm{Mo}$ & $\mathrm{W}$ & $\mathrm{V}$ \\
\hline M62 & Balance & 1.3 (max.) & 0.35 & 0.25 & 3.75 & 10.5 & 6.25 & 2.0 \\
\hline $\begin{array}{c}\text { M62 As-Cast } \\
\text { Electrode }\end{array}$ & 77.3 & 1.1 & 0.35 & 0.33 & 3.82 & 10.1 & 5.98 & 2.11 \\
\hline
\end{tabular}

\begin{tabular}{|l|c|}
\hline \multicolumn{2}{|c|}{ Table 2-Typical Properties of M62 } \\
\hline Hardness, Rockwell C & $65-67$ \\
\hline Elastic modulus, GPa & 235 \\
\hline Compressive Strength, MPa & 3,500 \\
\hline Density, g/cc & 8.17 \\
\hline
\end{tabular}

The second step is to combine the pure, raw constituents in the right proportions to form a cast M62 rod while preventing the introduction of any new contaminants. This is accomplished by combining and melting the M62 constituents (pure ingredients) inside a nonceramic (copper) crucible. For these experiments, the cold hearth skull melt process was employed in a plasmaheated vacuum furnace. With this method, an inert gas plasma heats the M62 constituents directly inside the crucible. The molten steel product is then poured under vacuum into molds to solidify. Analyses of the resulting M62 confirmed that no contaminant pickup (e.g., copper) occurred. Several trial runs were undertaken to fine-tune the ratios of the starting materials to yield a final composition within the desired range.

The third process step is to make powder from the ceramic-free M62 castings. This step is accomplished using the Electrode Induction Gas Atomization (EIGA) process. In the EIGA process, the cast ingot is machined into an electrode rod that is suspended inside a controlled 
atmosphere chamber. The rod is held vertically and slowly rotated while the lower end is positioned inside an induction-heating coil. The coil is energized, causing the surface of the rod (electrode) to melt forming large drops (drips) of high-purity M62. The effect is reminiscent of an icicle hanging from a building gutter that is slowly melting.

The M62 droplets fall into a high-speed, high-pressure stream of Argon gas where they are broken up into a fine spray of droplets. The droplets fall into the bottom of the chamber and solidify as they fall, forming high-purity powder. The walls of the atomizing chamber are made from metal (preferably steel) so that there is no chance of ceramic contamination of the powder.

The fourth process step is to take the ceramic-free, high-purity powder and consolidate the powder into solid, fully dense ingots from which bearings, gears, and other mechanical components can be made. In this process, the powder is poured inside a clean mild steel container; residual air and moisture are removed and a lid is welded onto the container, providing a hermetic seal. The can containing the loose M62 powder is then heated under pressure to form an ingot suitable for making bearings. Standard industry pressures and temperatures are used in the hot isostatic pressing (HIP) process as shown in Table 3.

\begin{tabular}{|l|c|}
\hline \multicolumn{2}{|c|}{ Table 3-Typical Consolidation Parameters for M62 } \\
\hline Temperature, ${ }^{\circ} \mathrm{C}$ & 1,121 \\
\hline Pressure, $\mathrm{MPa}$ & 102 \\
\hline Time, $\min$. & 180 \\
\hline
\end{tabular}




\section{Results and Discussions}

\section{Microstructure: Cast Electrode}

The M62 constituents were melted and then cast into electrodes that are subsequently atomized into M62 powder. Figs. 1a and 1b show backscattered electron micrographs of the resulting M62 electrode. In the photos, a dendritic structure with interdendritic carbides, typical for slowly cooled steel, is observed. Some of the microstructural features are quite long and exceed $200 \mu \mathrm{m}$. Chemical analyses or the resulting electrode were done using conventional methods (ICP-OES for the heavy elements, combustion-gas fusion for $\mathrm{C}$ and $\mathrm{O}$ ). The results (shown in table I) were mostly in line with the nominal composition of M62 with the exception of carbon which was slightly below specified levels $(1.25-1.35 \mathrm{wt} \%)$. Oxygen content was low $(0.001 \mathrm{wt} \%)$ for powder metallurgy products. It was speculated that some carbon may have been physically ejected from the crucible during electrode casting. In future trials additional carbon beyond the desired level may be introduced to counter the carbon loss observed. Nonetheless, the measured composition is sufficiently close to the published composition for M62 to indicate a successful proof-of-concept melt has resulted. 


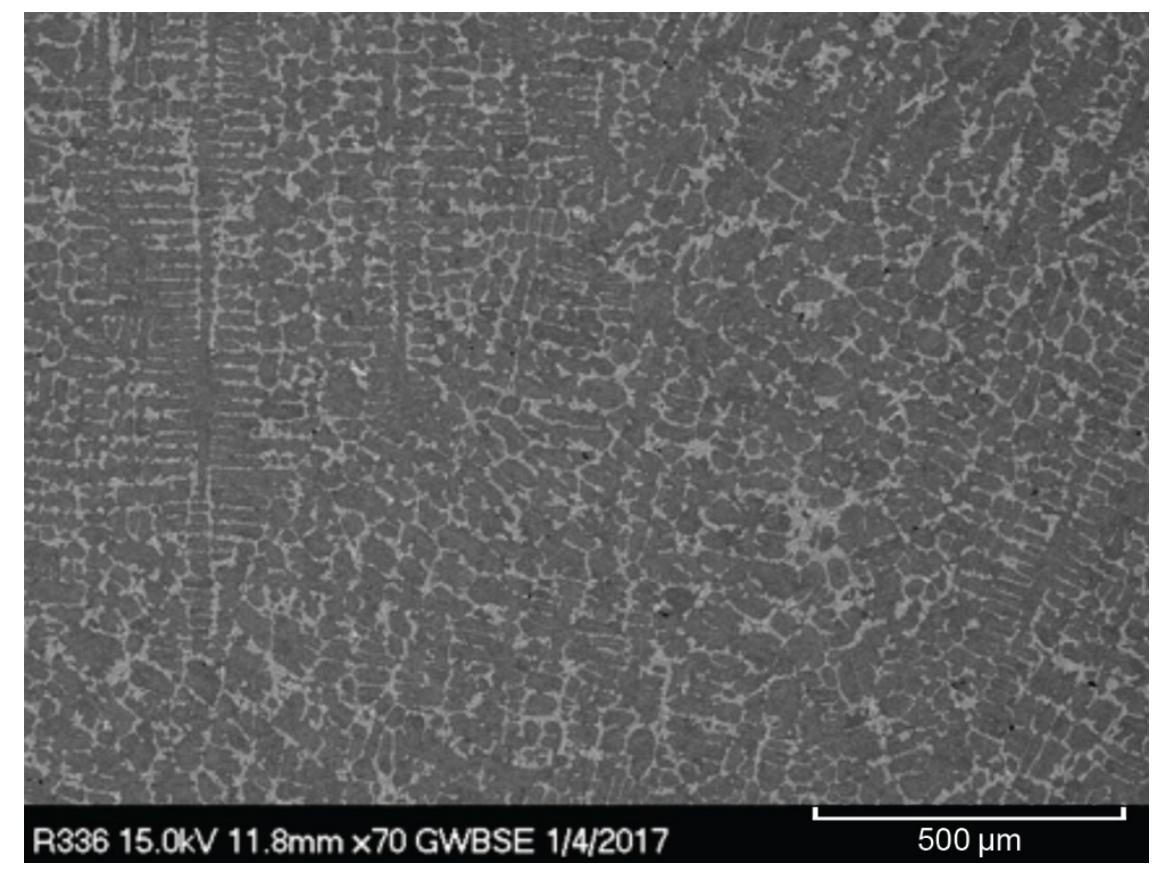

FIG. 1(a) The coarse dendritic structure with interdendritic lamellar carbide phase of the M62 following the casting step.

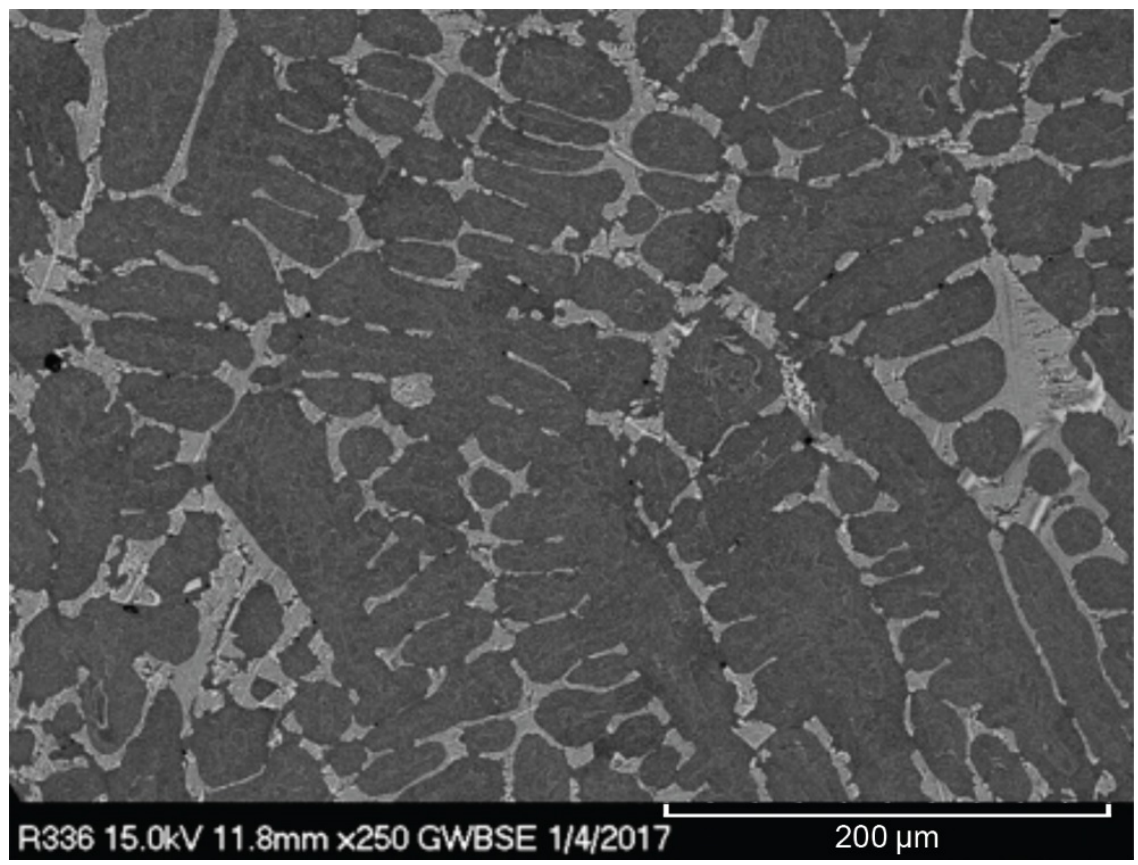

FIG. 1(b) Shows a higher magnification image M62 electrode, following the casting step. 
Fig. 2a is a higher magnification image that reveals more details of the as-cast structure. The darker gray matrix areas contain small spherically shaped carbides that surround extensive regions and networks of lamellae largely comprising Mo and W carbides as inferred from localized energy dispersive spectrum (EDS) analyses depicted in Figs. 2 a-c.

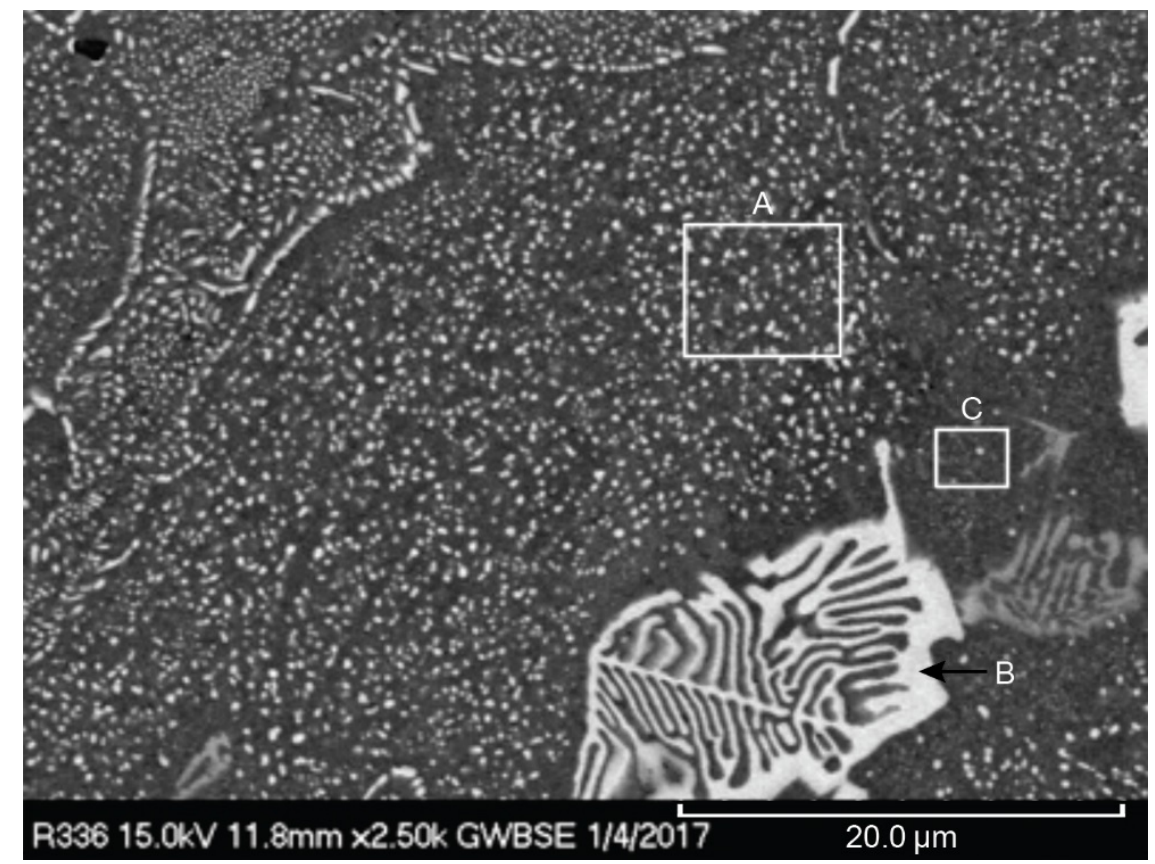

FIG. 2(a) Targets a local area that contains Fe-rich matrix regions (denoted as A and C) and W-Mo-C rich lamellae (e.g., [Mo, W] 6C eutectic structure) regions (denoted as region B).
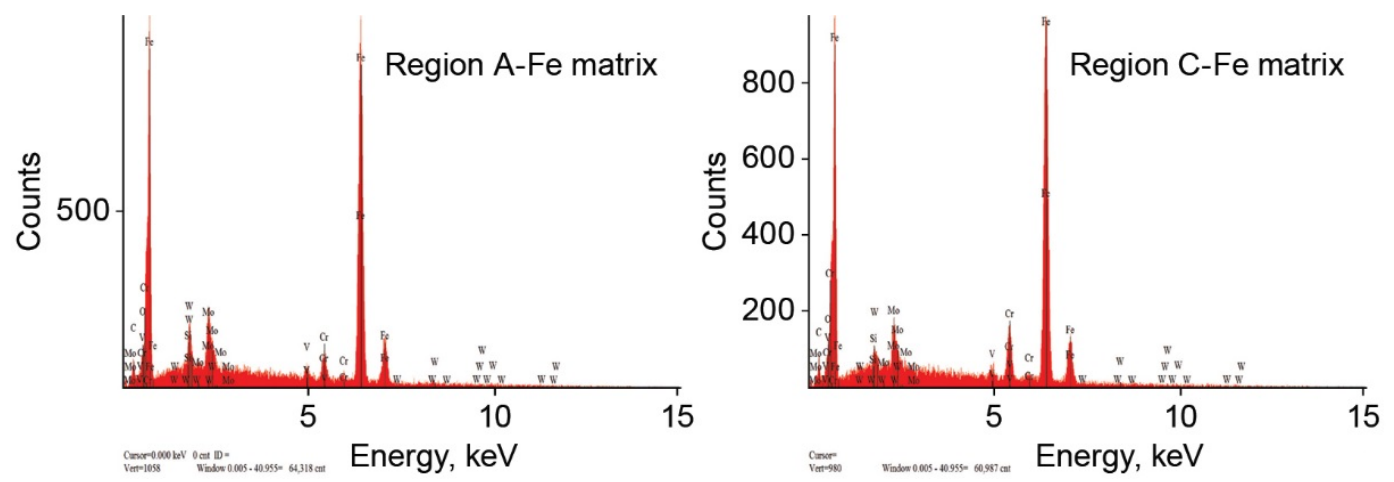

FIG. 2(b) EDS analyses for Fe-rich matrix regions (denoted as regions A and C in Fig.

2a). 


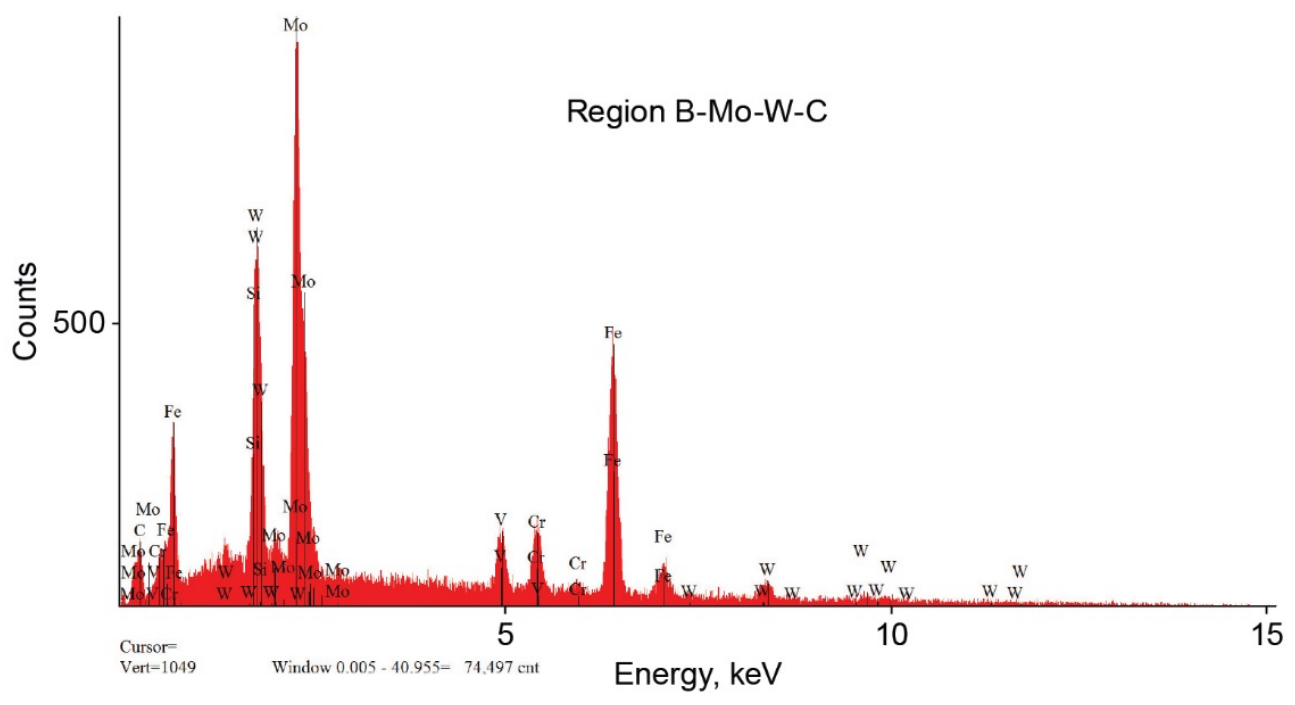

FIG. 2(c) EDS analysis for Mo-W-C rich lamellae structure region B in Fig. 2a.

A uniform, fine-grained and homogenous microstructure in which the largest carbides are less than $10 \mu \mathrm{m}$ in size is desired for rolling element bearings [5, 6, and 18]. Despite the high density and lack of contaminants, the coarse as-cast M62 microstructure is not suitable for bearings. For this reason, PM processes have been used to produce the desired fine-grained microstructures from M62.

\section{Powder Fabrication: Atomization of Cast Anode}

The cast M62 anode was atomized into a ceramic-free powder using an EIGA machine. The main details of the EIGA are depicted in Fig. 3. Briefly, the tip of the cast electrode is machined into a blunt cone shape. The electrode is then suspended from a rotating chuck inside the uppermost section of the argon-filled EIGA chamber. A drive motor slowly rotates the electrode while also feeding it in a downward direction into a conically shaped induction heating coil. The coil is energized such that the surface of the electrode tip melts, creating a layer of molten 
steel that drips through the open center of the heating coil into a gas nozzle positioned below. An argon gas stream impinges on the molten steel, breaking it into a fine spray, which then falls into the bottom section of the chamber.

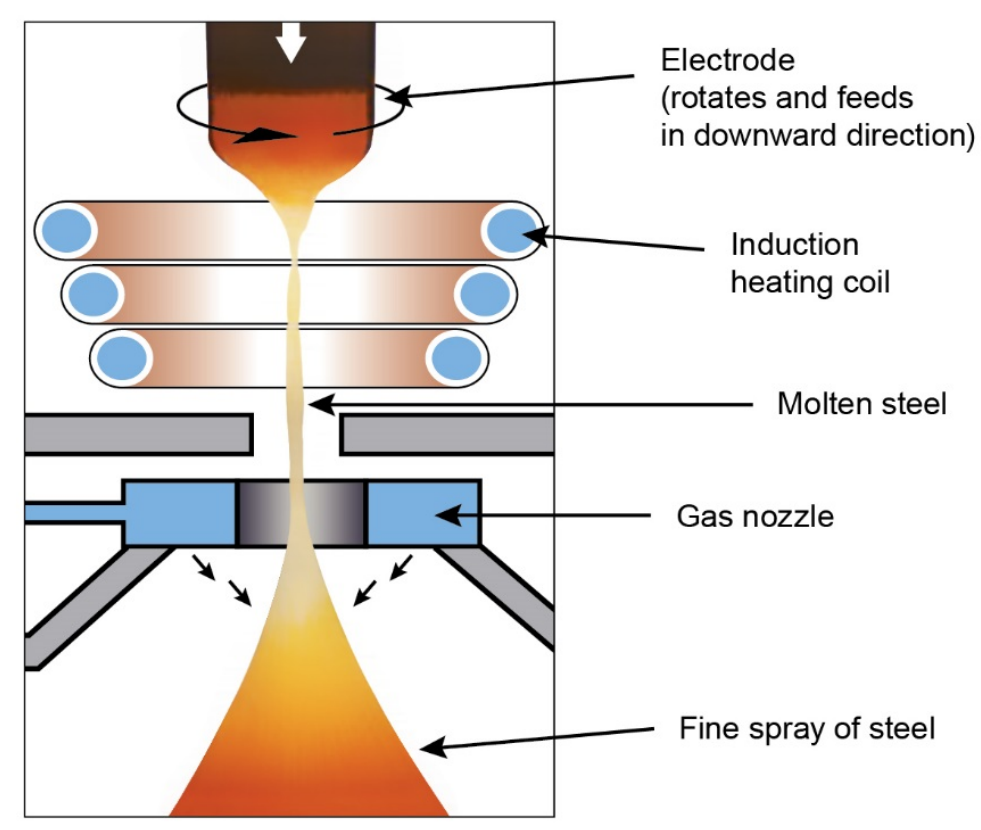

FIG. 3 Sketch of the EIGA process used to atomize the cast steel electrode into high-purity M62 powder. Image derived from (http://www.tls-technik.de/e 2.html).

While the spray falls, it cools and solidifies into powder. The resulting atomized powder is spherical in shape and largely free from porosity. More important, the powder is free from contamination because the EIGA process melts the electrode directly without any contact with a crucible or heating element. In addition, the atomization is done inside an argon gas-filled chamber, thus, the resulting powder only contains the constituents of the starting electrode. A sample of powder from two atomization trials was cross sectioned and examined under an optical microscope. The images are shown in Fig. 4. 

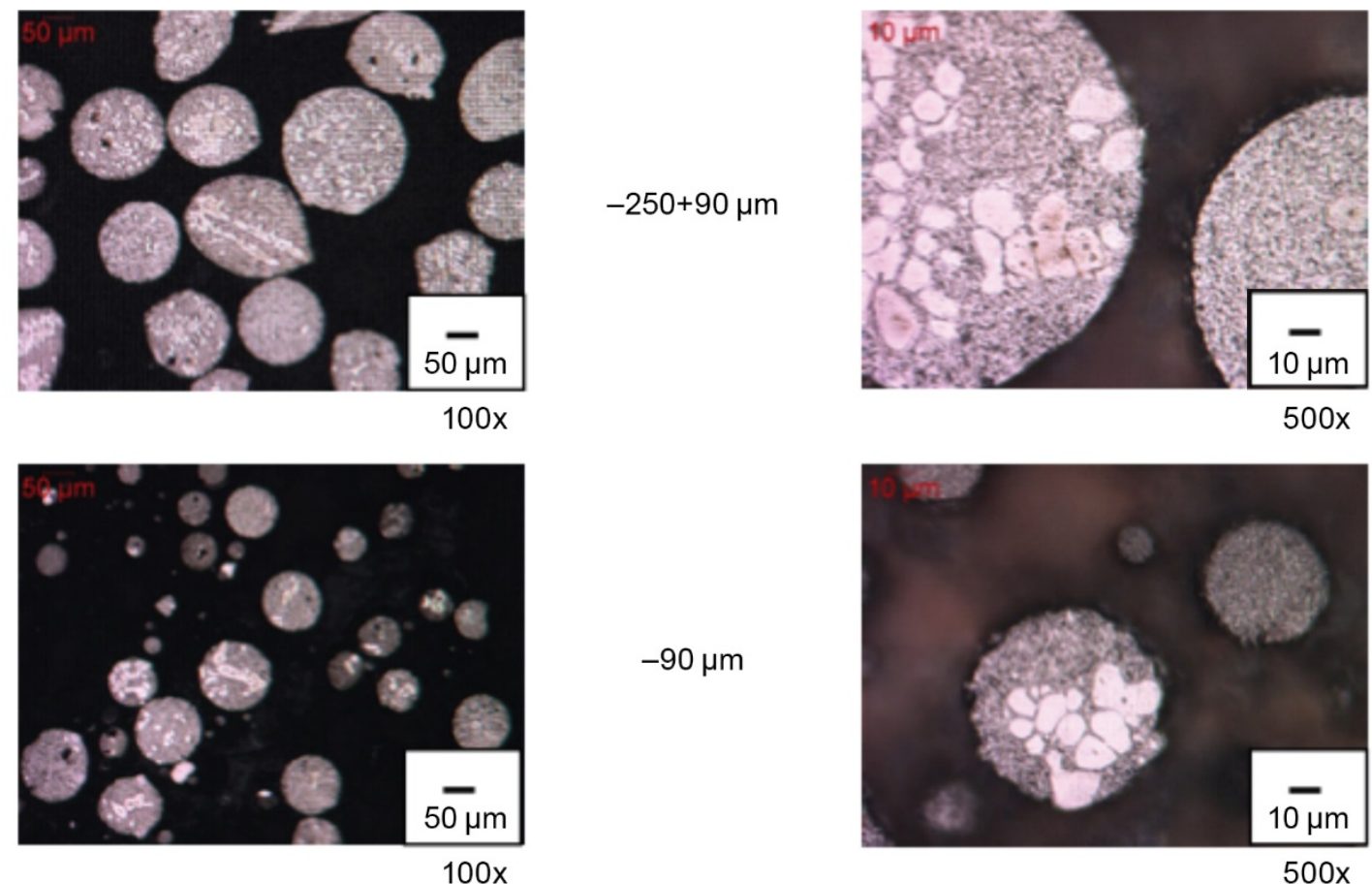

FIG.4 Optical microscopic image of powder made by atomization of the cast M62 electrodes. No inclusions or contaminants are observed.

\section{Powder Consolidation: Hot Isostatic Press}

The M62 powder is consolidated through HIP into a finished billet. Fig. 5 shows a schematic of the general HIP process.

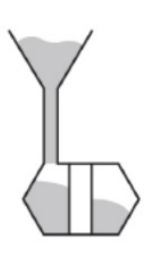

Fill can

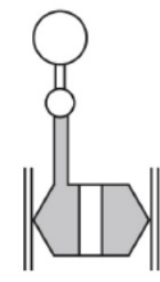

Vacuum bake-out

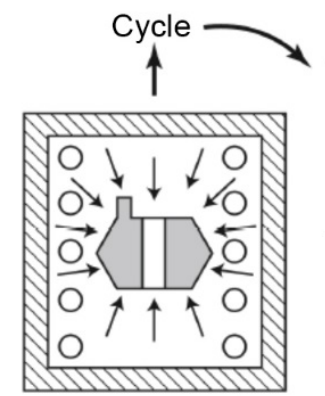

Hot isostatic press

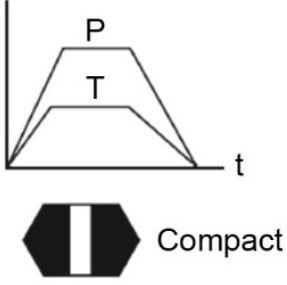

Remove can

FIG. 5 Schematic of the general HIP. Taken from NASA/TM-2015-218884. 
In the HIP process, the M62 powder is poured into a mild steel container that has the shape of the desired finished ingot. The container with powder is then heated under vacuum to remove all air and residual moisture, leaving only powder particles. The container is sealed, typically by welding, and then placed inside a high-pressure, high-temperature furnace. A predetermined timetemperature-pressure schedule is then applied to the steel container, which transmits the heat and pressure to the M62 particles, which consolidate and bond through solid-state diffusion. The process schedule is selected to promote complete consolidation, yet minimize grain growth and avoid melting. In this manner, the resulting compact is fully dense and fine grained. For the M62 ingot considered in this paper, the sealed container was subjected to a HIP temperature of $1,121{ }^{\circ} \mathrm{C}$ $\left(2,050^{\circ} \mathrm{F}\right)$ at $102 \mathrm{MPa}(14.75 \mathrm{ksi})$ pressure for 3 hours. A photograph of the first consolidated "Ultra-Clean" ceramic inclusion-free M62 ingot is shown in Fig. 6.

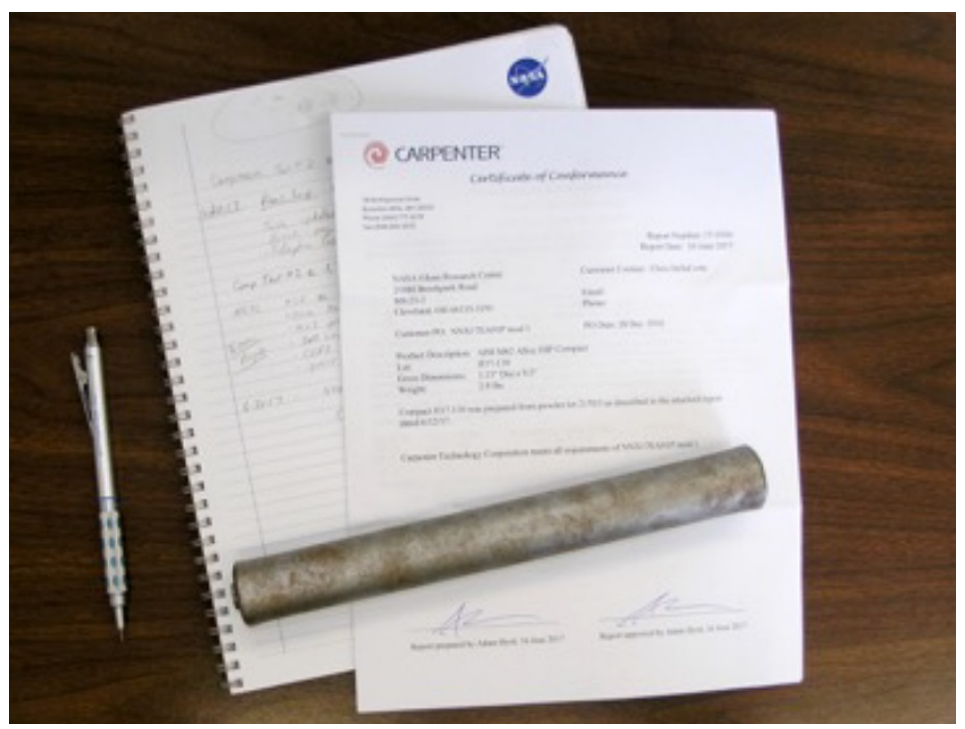

FIG.6 Photograph of first ceramic inclusion-free M62 ingot.

Sample slices cut from this ingot (Fig. 7) were evaluated for heat treatment response, 
hardness measurements, and microstructural analyses.

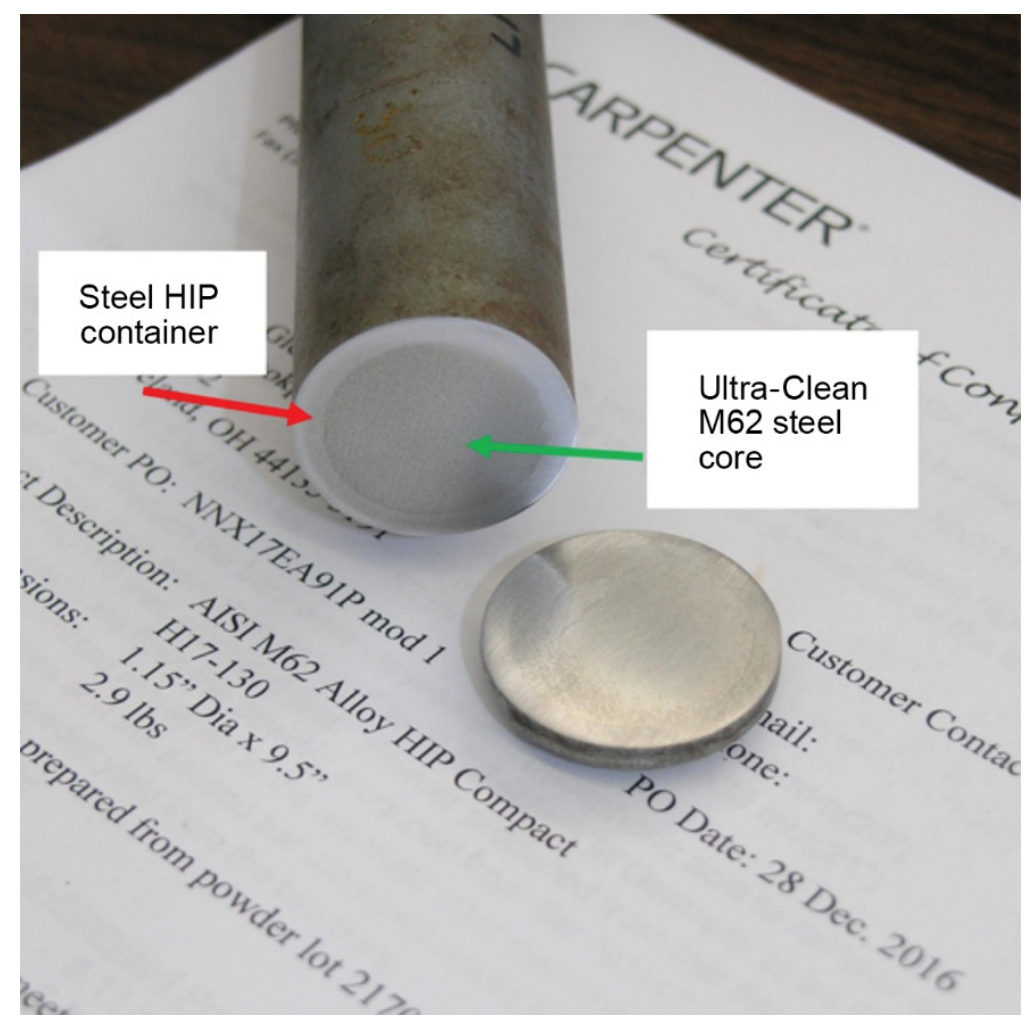

FIG. 7 Photograph of first ceramic inclusion-free M62 ingot.

Optical photomicrographs of polished cross sections taken in the as-HIP state, prior to heat treatment, are shown in Fig. 8.
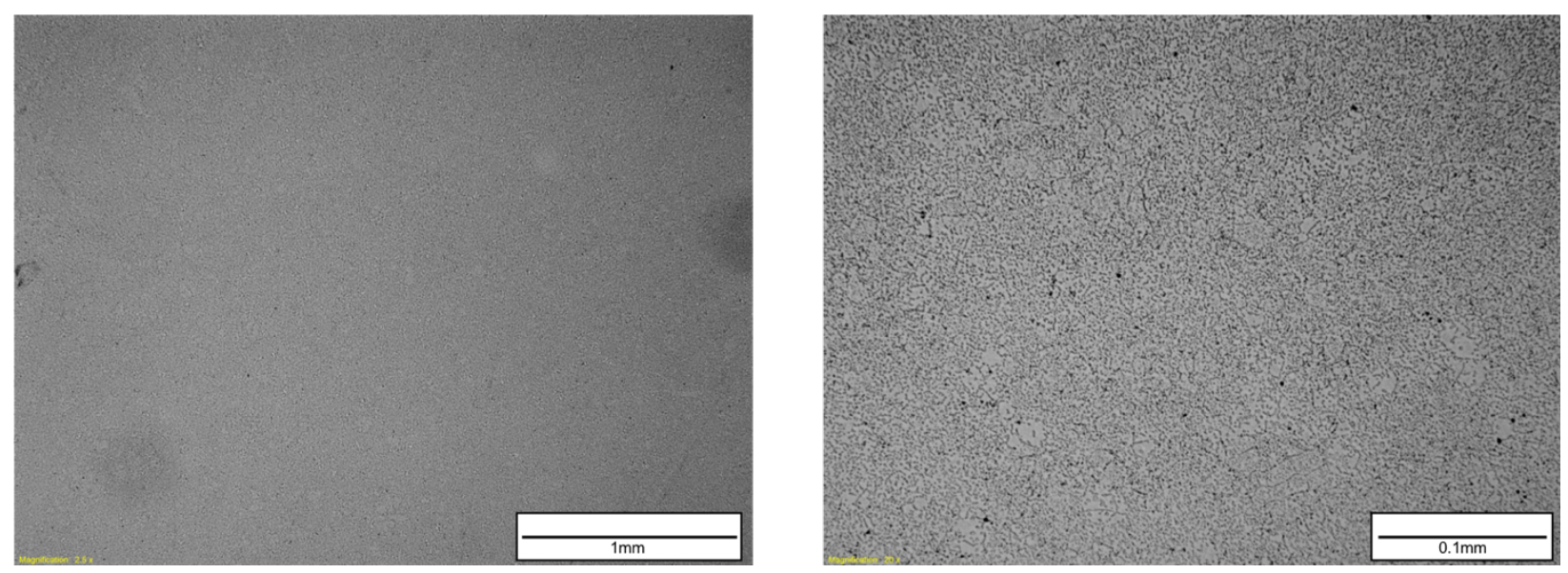

FIG.8 Optical micrograph of polished cross section as-HIP ceramic inclusion-free M62 ingot. 
The images of the polished section reveal a small number of micrometer-sized and submicrometer-sized pores and no other contaminants. Following heat treatment to increase hardness, additional microporosity develops. This is typical for PM steels that utilize gas-atomized powders. Small amounts of dissolved argon gas, incorporated into the powder during atomization, are thought to coalesce into small additional pores during heat treatment. In Fig. 9, these additional pores can be seen as black dots in the optical micrographs. To aid comparisons of the pre- and post-heat treat micrographs, the images in Figs. 8 and 9 are taken at the same magnification level.
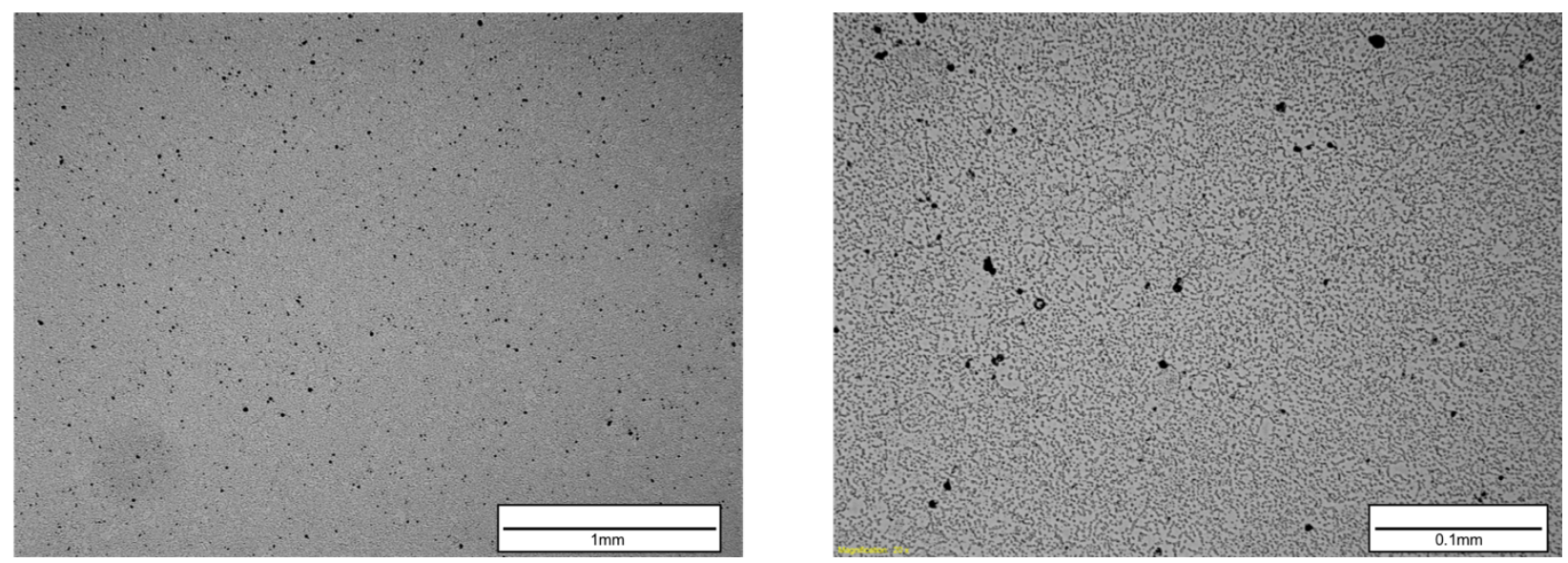

FIG. 9 Optical micrograph of polished heat-treated ceramic inclusion-free M62 ingot.

Scanning electron microscopy (SEM) is an effective tool to inspect the microstructure and elemental distribution of steel. Coupled with an x-ray detector, the SEM can easily identify different phases, evaluate pores and voids, and locate and characterize any contaminant phases or ceramic inclusions, if present. Another characteristic of the SEM is that the resulting photographs depict the heaviest (atomic mass) elements, such as $\mathrm{Mo}, \mathrm{W}, \mathrm{V}$, and $\mathrm{Cr}$, as bright areas with the 
lightest elements (such as the $\mathrm{Al}$ and $\mathrm{Si}$ found in conventional steel's ceramic inclusions, $\mathrm{Al}_{2} \mathrm{O}_{3}$ and $\mathrm{SiO}_{2}$ ) as dark areas. The SEM can also readily determine the size and shape of carbides and other features. Fig. 10 is an SEM image of the as-HIP Ultra-Clean M62.

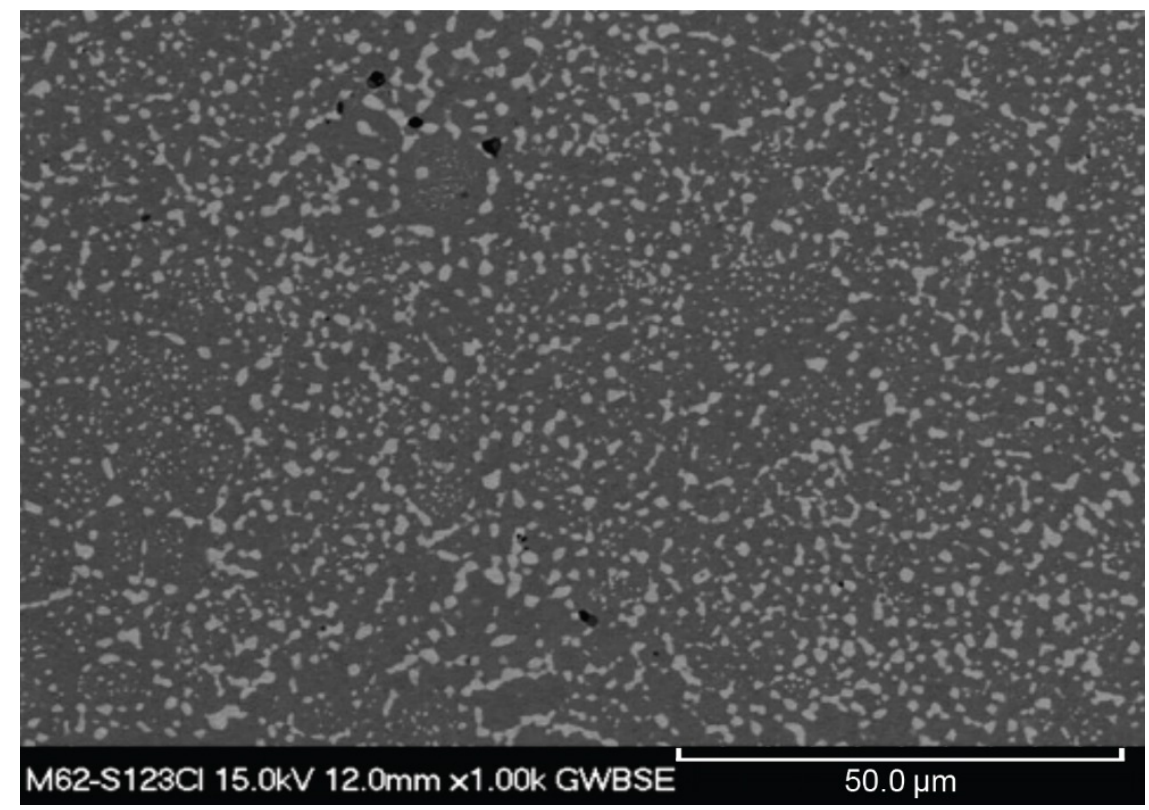

FIG. 10 SEM backscattered micrograph of polished cross section of as-HIP ceramic inclusion-free M62 ingot. Lightest areas correspond to phases with the highest atomic mass elements (W, Mo, V, and Cr). Black spots are residual pores and concentrations of Mn.

In the SEM, the electron beam can specifically target different (brightness) regions to identify the elements present and deduce the phase compositions. When pointed at the darker gray matrix areas (between the brighter carbide spots), the resulting $\mathrm{X}$-ray spectra indicates that $\mathrm{Fe}$ is the dominant constituent as shown in Fig. 11. 


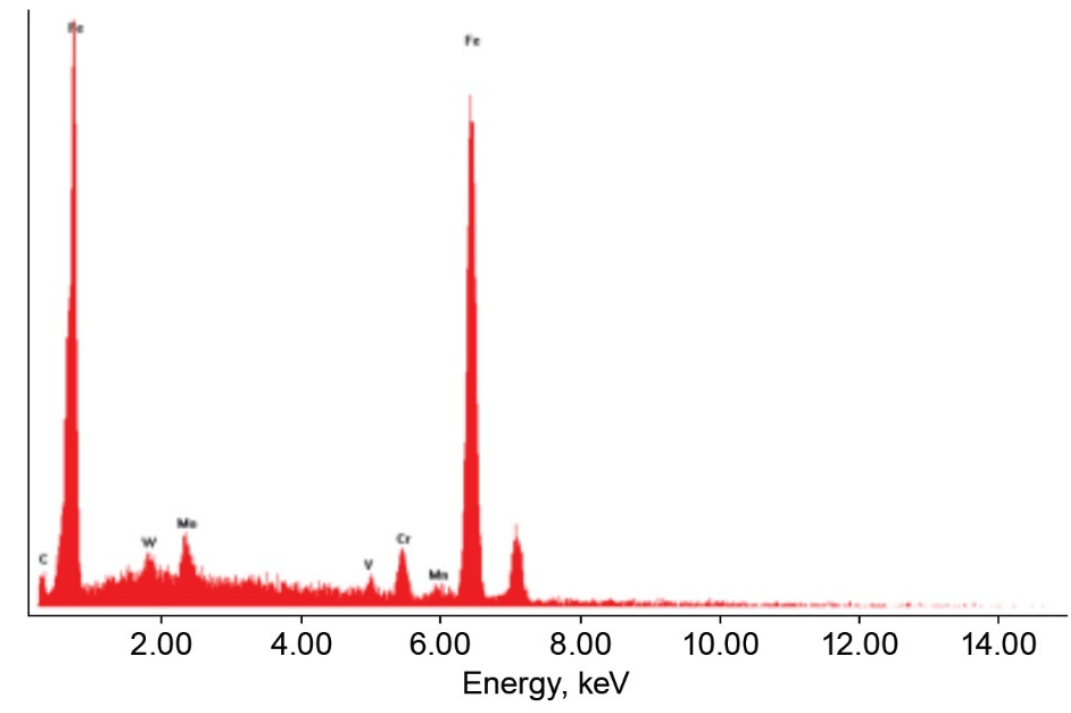

FIG. 11 X-ray spectrum of polished cross section of as-HIP ceramic inclusion-free M62 targeted at the matrix (dark gray region between the bright carbide spots).

In this spectrum (Fig. 11), the largest peaks correspond to iron while the other minor elements are also present at lower levels. Since the incident electron beam that creates the x-rays penetrates the sample and is spread upon contact, the x-rays generated pick up faint signals from adjacent areas of the sample. Hence, the other elements in M62 (Mo, W, V, Cr, and Mn) are weakly displayed in the spectrum, even though the targeted (dark gray) area is only expected to be made up predominantly of iron. In contrast, the spectrum from an analysis location centered on a bright phase region is shown in Fig. 12. 


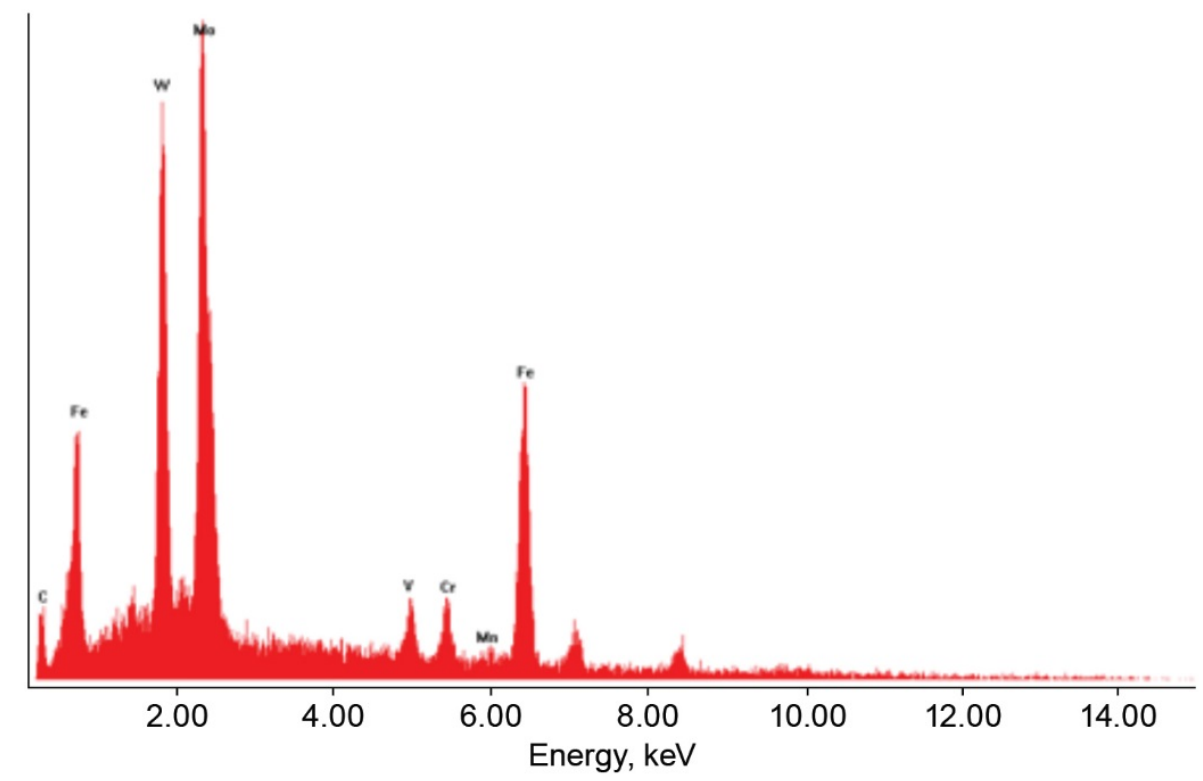

FIG. 12 X-ray spectrum of polished cross section of as-HIP ceramic inclusion-free M62 targeted at the carbide phases (bright spherical regions surrounded by dark gray matrix).

In this spectrum (Fig. 12), the largest peaks correspond to the carbide-forming elements, namely, Mo, W, V, and Cr. As in the spectrum before, the excitation beam spreads and penetrates and creating a faint signal for $\mathrm{Fe}$ and $\mathrm{Mn}$.

Samples from the HIP ingot were heat treated to develop high hardness. The process for heat treatment is complex and involves vacuum heating at $1,180{ }^{\circ} \mathrm{C}$, followed by rapid inert gas cooling to room temperature. The material is then further processed with three $540{ }^{\circ} \mathrm{C}$ tempercooldown to $25^{\circ} \mathrm{C}$ cycles. Final hardness ranged from Rockwell C65 to C68. Polished sections of hardened M62 are shown in Fig. 13. 


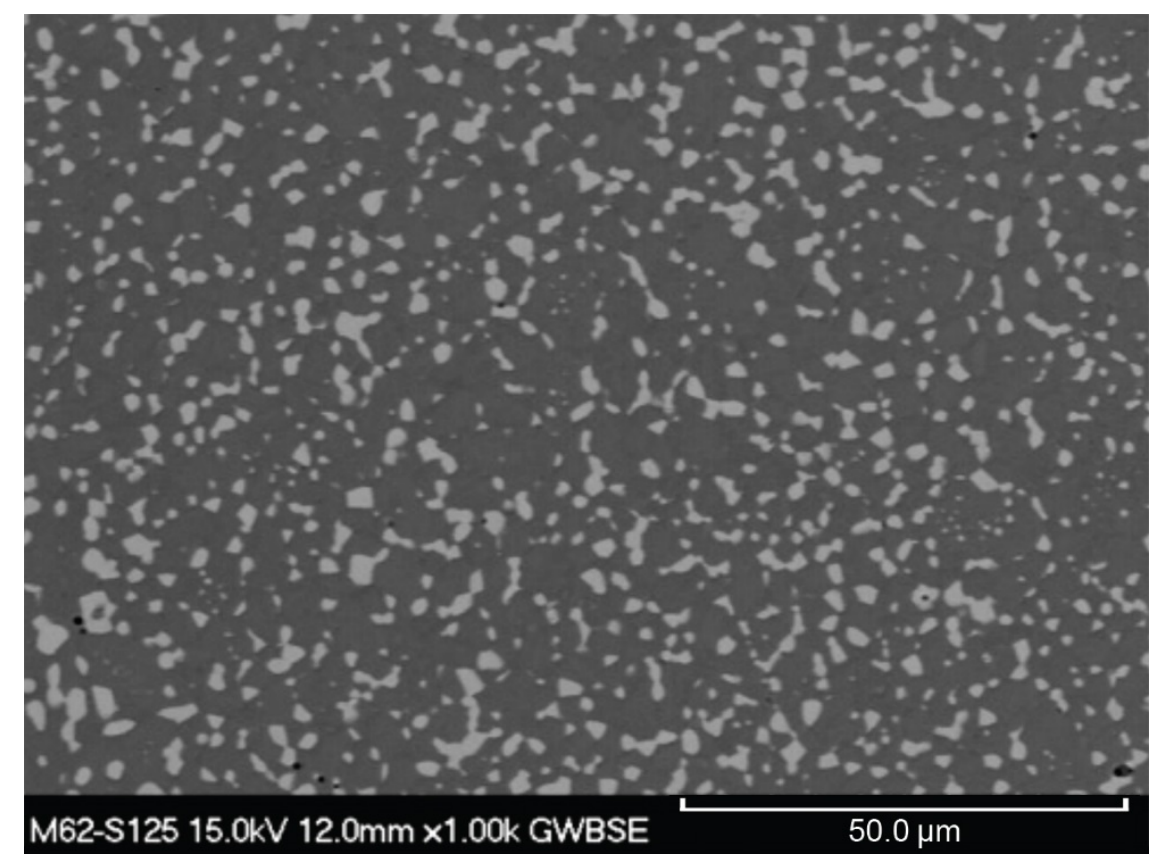

FIG. 13 SEM backscattered micrograph of polished cross section of heat-treated ceramic inclusion-free M62 ingot. Lightest areas correspond to phases with the highest atomic mass elements (W, Mo, V, and Cr).

The heat treatment has slightly coarsened the microstructure. The carbide (hard) phases are rounder and larger than in the as-HIP condition (Fig. 10) and the matrix regions are broader. Such a change is expected and typical for high-carbide steels. This microstructure is suitable for bearings and other high-performance applications.

For use in ball bearing products, M62 is often hot worked (deformed) before heat treatment to minimize microporosity and refine the microstructure. For the present investigation, hot extrusion at $1,120{ }^{\circ} \mathrm{C}$ with approximately 5 to 1 area reduction ratio was employed. Fig. 14 shows the resulting microstructure. 


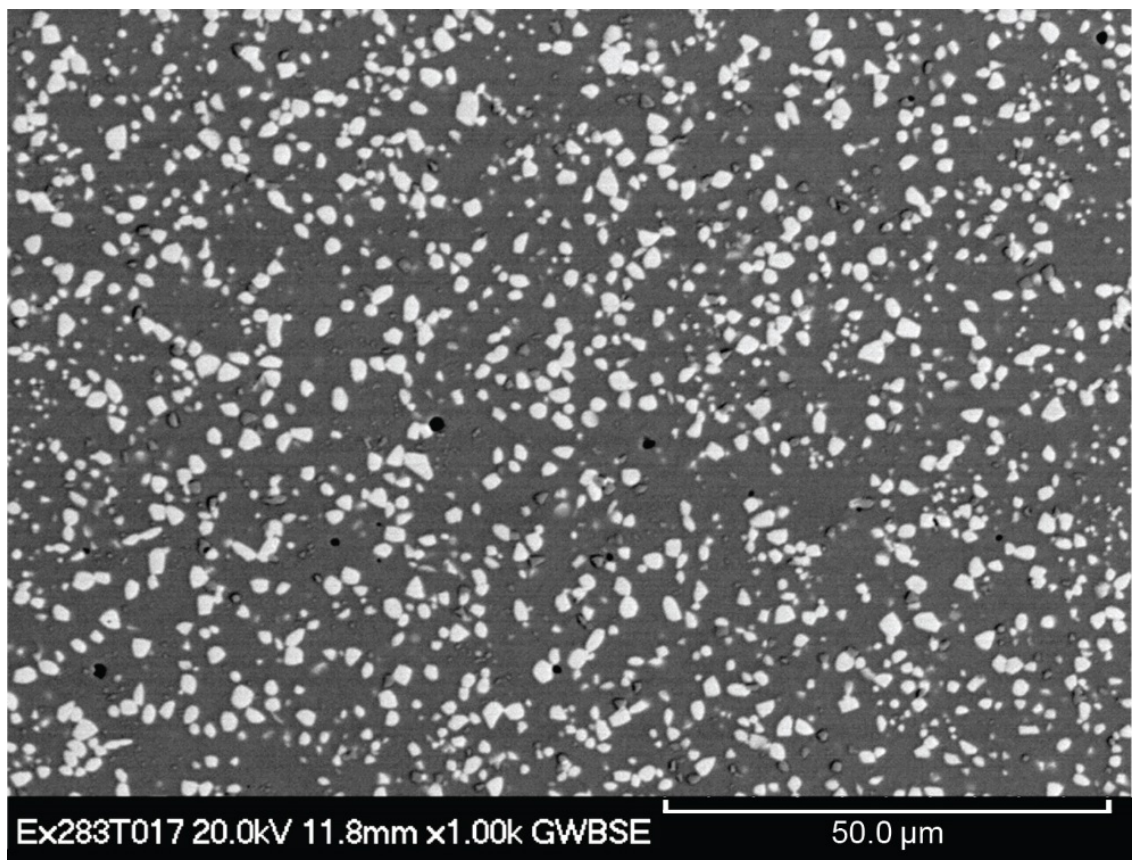

FIG. 14 SEM backscattered micrograph of polished cross section of hot-extruded ceramic inclusion-free M62 ingot.

Comparing the microstructure before and after extrusion, it appears that the hot working has resulted in a slightly finer and more homogenous distribution of carbides. Further, the carbides are more rounded. In comparison to commercially sourced M62 made using conventional PM processes, the "Ultra-Clean" process presented in this paper is remarkably similar. In Fig. 15 below, the micrograph of commercially prepared M62 (cast and hot worked) is presented at the same magnification as Fig. 14. 


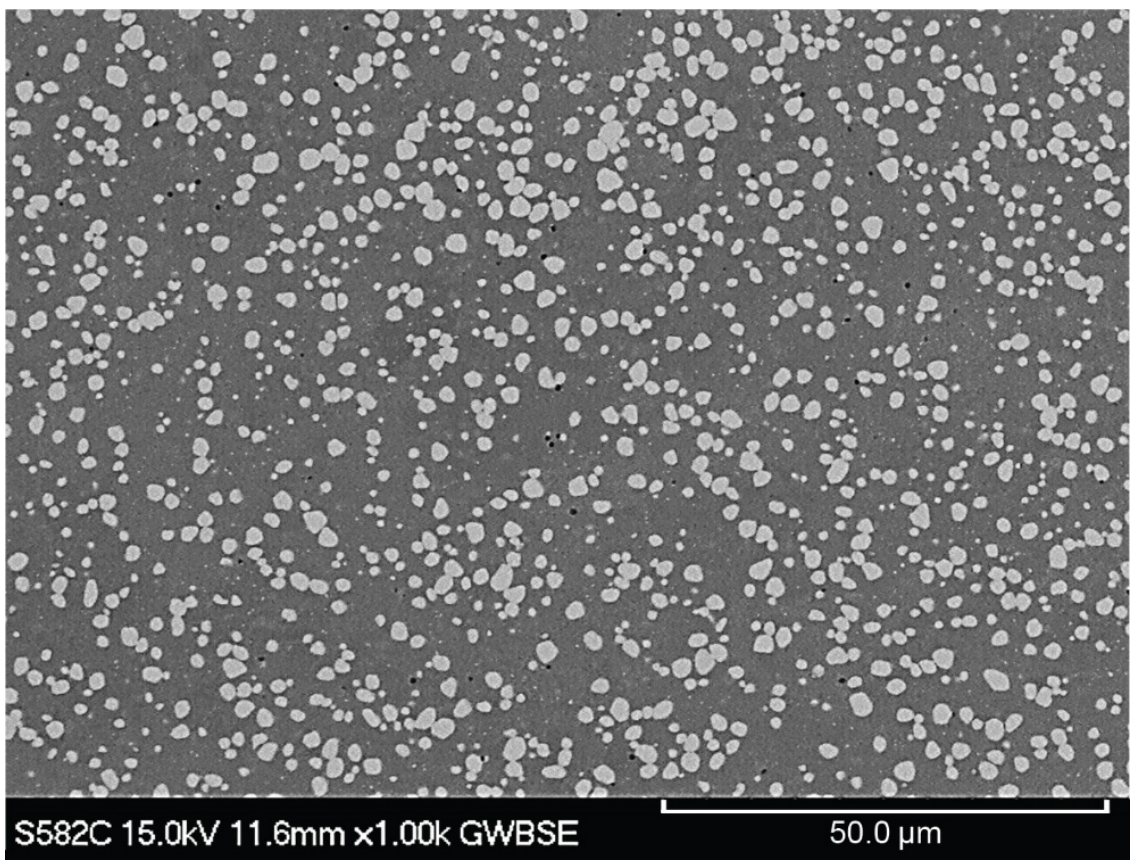

FIG. 15 SEM backscattered micrograph of polished cross section of commercially prepared M62.

From a microstructure point of view, the M62 produced using the ceramic-free process steps put forth in this paper is comparable to commercially sourced material.

\section{Discussion}

The research described in this paper demonstrates that the processes employed to make bearing-grade NiTi alloys can be applied to the high-carbide tool steel M62. The process represents several key departures from conventional steelmaking and several similarities. While the process reduces several entry points for ceramic inclusions, others remain. In general, conventional melt pathways produce steel with fewer inclusions than PM routes. However, inclusions in PM products tend to be smaller sized, typically no larger than the average particle diameter of the feedstock, whereas in conventional cast materials the inclusion size is not so limited. Thus, unwanted inclusions can and do arise in both processes. 
Sourcing elementary pure constituents is straightforward. However, compared to using steel as the feedstock, the elemental method carries additional risks and cost. Purified elements are expensive. In addition, for each element needed, there is risk that the handling of the materials (multiple shipping containers, tools, and fixtures used for weighing and transferring multiple elements) can introduce contamination. Since the process described in this effort does not include any means to purify the steel, inadvertent contaminates will remain in the product. Additionally, other than the utilization of plasma heating and the cold hearth skull melt process in a vacuum furnace and induction-based powder atomization equipment, the process used in this paper largely mimics the conventional PM processes in use for the last few decades to make such high-carbide steels. Thus, the present process can suffer from contamination introduced in downstream (from the powder fabrication step) steps such as pick up of contamination from residual materials left in process machinery.

As an example, during the research program, a relatively large ceramic $\left(\mathrm{TiO}_{2}\right)$ inclusion $(\sim 20 \mu \mathrm{m})$ was observed in an ingot near the wall of the extrusion container. Initially, it was presumed that this particle originated from the inside wall of the extrusion can or as a tramp particle adhered to the outer surface of the steel sample prior to canning. Later investigation determined that the particle likely originated in the starting powder. The EIGA atomizing machine used to make powder is a multipurpose facility. To ensure no carryover from one atomization project to another, a cleaning run is conducted in which an electrode of the desired product in atomized and then removed from the chamber and set aside for recycling. In this manner, any residual materials left over from previous work are expected to be flushed with the cleaning run. Concerning the $\mathrm{TiO}_{2}$ inclusion discovered in the present case, it was learned that the M62 powder from the cleaning run was inadvertently used to make an M62 ingot. It was in this ingot made from the powder intended 
only for recycling that the inclusion was detected. The lesson learned is that human error can result in a contaminated product just as it can for conventional processes. Thus, the method put forth in this paper offers the potential to avoid contamination resulting from the incomplete removal of ceramic contaminants present in the starting materials used in conventional steelmaking, but it is not foolproof.

Ultimately, it remains to be proven whether the M62 free from ceramic inclusions can provide equal or superior operational performance in highly loaded ball bearings and other critical applications. Based upon the high level of cleanliness and the homogeneous microstructure, the potential for this process appears to be encouraging. Further, the ceramic-free nature of each of the processing steps alone could be adopted into conventional steelmaking processes to help reduce the frequency of unwanted ceramic particle occurrences.

\section{Summary}

The approach and methods developed to produce inclusion-free NiTi alloys have been successfully applied to the production of the high-carbide content, high-performance bearing steel M62. The fundamental materials engineering approach initiates the process using laboratorygrade, elemental constituents and prevents their contamination by employing state-of-the-art ceramic-free processing. The elements were melted and formed into a billet. The billet was atomized in an inert gas environment to form high-grade powder. Wet chemical analysis of the powder indicated that no unintentional elements were added during powder fabrication. The powder was then consolidated through the hot isostatic pressing (HIP) method into a ceramic-free, fully dense M62 compact.

Polished and acid-etched cross-section specimens were made from the resulting compact 
and analyzed using optical microscopy and scanning electron microscopy (SEM) in conjunction with X-ray analysis. In the final product, only the elements present in the original composition were detected. Though this effort is still at the preliminary stage, no undesirable ceramic inclusions (such as aluminum oxide) that could diminish performance were found. The resulting product is free from contamination that could potentially degrade the performance of advanced bearings and other products. The methods used to make this specialty steel can be applied at any batch volume size, thus, promoting the development and use of "boutique alloys" that might otherwise be uneconomical. Further, the process is robust and may allow the minimization or elimination of expensive and potentially ineffective inspections and quality control assessments of steel prior to making bearings.

\section{ACKNOWLEDGMENTS}

The author wishes to acknowledge the funding support of the NASA Engineering and Safety Center (NESC). In particular, the interest and support provided by Dr. Michael J. Dube, leader of the Mechanical Systems Discipline Team, and NESC Chief Engineer at NASA Glenn, Dr. Robert Jankovsky, have been pivotal in the success of this project.

The technical support and collegial discussions from Mr. Eric Bono and Mr. C. Fred Yolton of Carpenter Powder Technology (Carpenter Technology Corporation) has been invaluable. Their efforts to implement my vision for absolutely pure steel has been instrumental.

Technical discussion with NASA colleagues Dr. Ron Noebe and exemplary SEM provided by Ms. Anita Garg as well as the "can-do" spirit and support in the lab by Mr. Fransua Thomas, who implemented a suitable heat treatment for the material and prepared metallographic cross sections, greatly aided the project. 


\section{References}

[1] Park, W., Hilton, M. R., Ward, P. C., Henderson, G. W., Leveille, A. R., McClintock, D. E. and Smith, D. W., "Microstructure, Fatigue Life and Load Capacity of PM Tool Steel REX20 for Bearing Applications,” Lubr. Eng., Vol. 55, No. 6, 1999, pp. 20-30.

[2] Park, W., Hilton, M. R., Ward, P. C., Henderson, G. W., Leveille, A. R., McClintock, D. E. and Smith, D. W., "Rolling Contact Fatigue and Load Capacity Tests of M62 Bearing Steel," Proceedings of the 32nd NASA Aerospace Mechanisms Symposium, NASA/CP-1998-207191, 1998, pp. 237-253.

[3] Smith, D. W., Leveille, A. R., Hilton, M. R. and Ward, P. C., "REX 20/Si3N4 Control Moment Gyroscope Bearing Development," Proceedings of the 32nd Aerospace Mechanisms Symposium, NASA/ CP-1998-207191, 1998, pp. 223-235.

[4] Pearson, P. K., Moll, J. H., Hannigan, C. J. and Atwell, D. R., "Evaluation of P/M Tool Steels for Bearing Applications," Advances in Powder Metallurgy and Particulate Materials, 1994: Proceedings of the 1994 International Conference \& Exhibition on Powder Metallurgy \& Particulate Materials, Toronto, Canada, May 1994, Metal Powder Industries Federation, Princeton, NJ, pp. 155-163.

[5] Fuchs, E. and Johnson, P., "Inclusion Characteristics in Bearing Steel Before and During Ingot Casting," High Temp. Mater. Proc., Vol. 19, No. 5, 2000, pp. 333-343.

[6] Pretorius, E. B., Oltmann, H. G. and Schart, B. T., “An Overview of Steel Cleanliness From an Industry Perspective," AISTech-The Iron and Steel Technology Conference and Exposition Proceedings, Pittsburgh, PA, Jan. 2013, pp. 993-1026.

[7] Beretta S. and Murakami, Y., "Largest-Extreme-Value Distribution Analysis of Multiple Inclusion Types in Determining Steel Cleanliness," Metall. Mater. Trans. B, Vol. 32, 2001, pp. 
$517-523$.

[8] DellaCorte, C., Pepper, S. V., Noebe, R., Hull, D. R. and Glennon, G., "Intermetallic Nickel-Titanium Alloys for Oil-Lubricated Bearing Applications,” NASA/TM-2009-215646, 2009.

[9] DellaCorte, C., Noebe, R., Stanford, M. K. and Padula, S. A., "Resilient and CorrosionProof Rolling Element Bearings Made From Superelastic Ni-Ti Alloys for Aerospace Mechanism Applications," NASA/TM-2011-217105, 2011.

[10] Stanford, M. K., "Charpy Impact Energy and Microindentation Hardness of 60NITINOL,"NASA/TM-2012-216029, 2012.

[11] Buehler, W. J., "Intermetallic Compound Based Materials for Structural Applications," The Seventh Navy Science Symposium: Solution to Navy Problems Through Advanced Technology, Pensacola, FL, May 14-16, 1963, Office of Naval Research, Arlington, VA.

[12] Kingery, W. D., Bowen, H. K. and Uhlmann, D. R., “Introduction to Ceramics," Second ed., Ch. 15, J. Wiley \& Sons, New York, NY, 1976, pp. 768-815.

[13] MSFC-SPEC-3706: Specification for 60Ni-40Ti Billets, National Aeronautics and Space Administration, Washington, DC, 2016.

[14] DellaCorte, C. and Glennon, G., "Ball Bearings Comprising Nickel-Titanium and Methods of Manufacture Thereof,” U.S. Patent 8,182,741, May 22, 2012.

[15] DellaCorte, C. and Glennon, G., "Compositions Comprising Nickel-Titanium and Methods of Manufacture Thereof," U.S. Patent 8,377,373, Feb. 19, 2013.

[16] Padula, S. A., Noebe, R. D., Stanford, M. K. and DellaCorte, C., "Mechanical Components From Highly Recoverable, Low Apparent Modulus Materials,” U.S. Patent 9,169,545, Oct. 27, 2015. 
[17] DellaCorte, C. and Glennon, G., "Compositions Comprising Nickel-Titanium and Methods of Manufacture Thereof and Articles Comprising the Same," U.S. Patent 9,393,619, July 19, 2016. [18] Ge, J., "Process Simulation and Inclusion Characterization in Stainless Steel Ingot Casting," Master's Thesis, Missouri University of Science and Technology, 2012.

[19] Crucible Industries: DS326-CPM Rex 20 Data Sheet, http://www.crucible.com/PDFs// DataSheets2010/ds20rev1\%202010.pdf (accessed April 1, 2019). 